\title{
Notice of Triplicate Publication
}

The editors of Digestion, Alimentary Pharmacology \& Therapeutics, and Hepatogastroenterology regret to announce that they have detected triplicate publication of what is essentially the same paper from the same authors. The titles and references of the papers are as follows:

R. Alcala Santaella, J. Guardia, J. Pajares, J. Pique, L. Pita, E. Alvarez, P. Castellanos, L. Guamer, J. Ortiz, R. Pesquera, V. Vargas, R. Ruiz-Capellan

A multicentre, randomised, double-blind study comparing nocte famotidine or ranitidine for the treatment of active duodenal ulceration Aliment Pharmacol Ther 1989;3:103-110

A multicentre, randomised, double-blind study comparing a daily bedtime administration of famotidine and ranitidine in short-time treatment of active duodenal ulcer Digestion 1989;44:79-85

A multicentre, randomised, double-blind study comparing a once-daily bedtime administration of famotidine and ranitidine in the short-term of active duodenal ulcer Hepatogastroenterology 1989;36:168-171

The authors represent the following institutions: Hospital Gregorio Maranon, Madrid (R. Alcala Santaella, P. Castellanos); Hospital Valle de Hebron, Barcelona (J. Guardia, L. Guarner, V. Vargas); Hospital de la Princesa, Madrid (J. Pajares, J. Ortiz, R. Pesquera); Hospital Clinico y Provincial, Barcelona (J. Pique); Hospital Hermanos Laguna, Madrid (L. Pita, E. Alvarez); Merck, Sharp \& Dohme de Espana, SA Spain (R. Ruiz-Capellan) 